\title{
"La voz de nuestra generación", mural develado en la Benemérita Universidad Autónoma de Aguascalientes, en homenaje a los brigadistas contra la coviD-19
}

Departamento de Formación y Actualización Académica

$\mathrm{E}$ n el campus central de la Benemérita Universidad Autónoma de Aguascalientes (UAA), fue develado el mural "La voz de nuestra generación", obra impulsada por la Federación de Estudiantes de la UAA (FEUAA) para rendir homenaje a los más de 900 brigadistas que han apoyado en la Jornada Nacional de Vacunación contra la COVID-19, tanto en la capital como en el resto de los municipios de Aguascalientes. "El evento fue presidido por el Gobernador del Estado, C.P. Martín Orozco Sandoval; el Dr. en C. Francisco Javier Avelar González, rector de la institución; el artista gráfico Ricardo Martínez "Trazo", autor del mural; así como integrantes de la FEUAA" (UAA, 2021). Durante la develación, el C.P. Martín Orozco Sandoval destacó la activa participación de los jóvenes aguascalentenses para acudir a la aplicación de la vacuna, así como la entrega y el espíritu solidario de los integrantes de la UAA, quienes, mediante el trabajo colectivo y entusiasta, han logrado acciones de alto impacto en beneficio de la población y el desarrollo de la entidad. Por su parte, el rector de la institución, el Dr. en C. Francisco Javier Avelar González, hizo un reconocimiento a toda la comunidad universitaria que, en el marco de esta crisis sanitaria, se han volcado en apoyo a la sociedad, reconociendo su participación en el emprendimiento de "acciones como la producción de insumos desde los primeros meses de la pandemia y el apoyo a las iniciativas institucionales en beneficio de los sectores vulnerables" (UAA, 2021). Por otro lado:

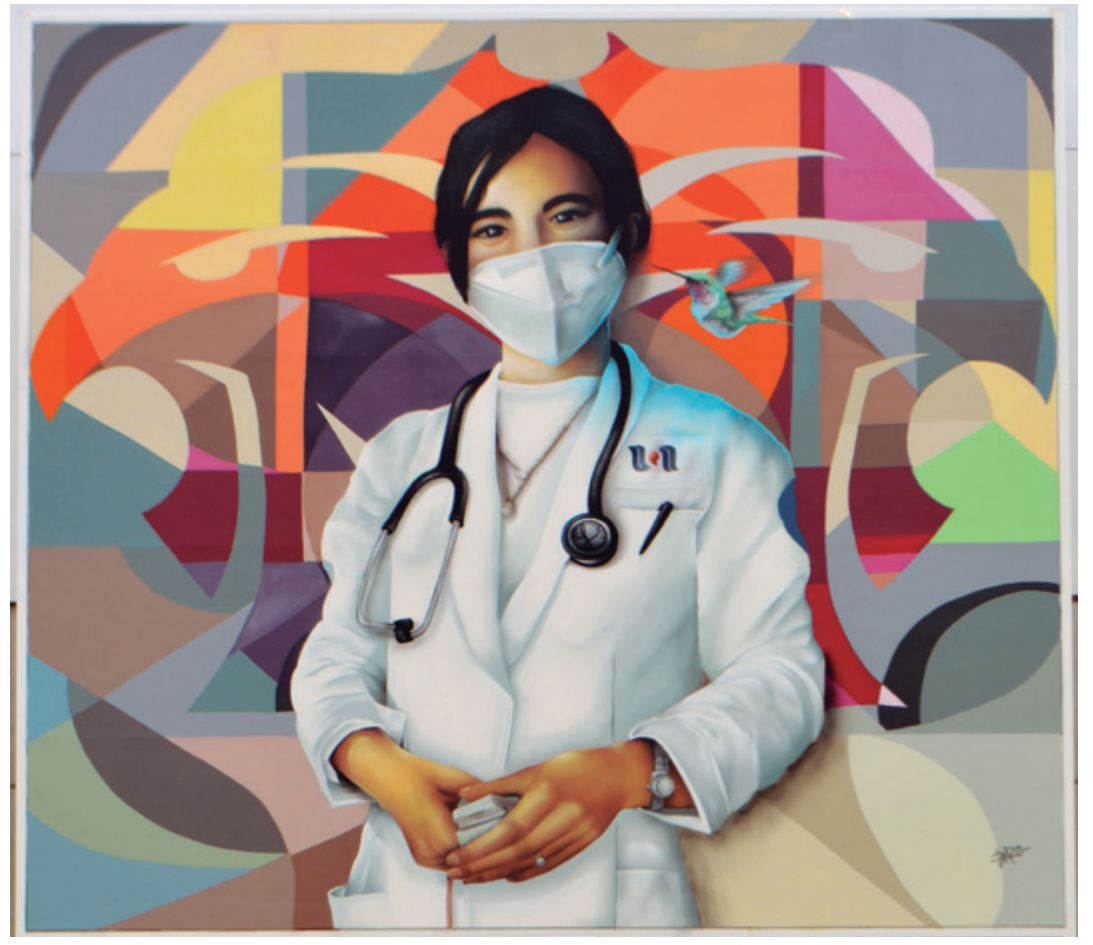

El artista gráfico Ricardo Martínez “Trazo” agradeció a la máxima casa de estudios de la entidad por la confianza de brindarle un espacio para su obra, un mural que permanecerá en el exterior del edificio Polivalente "Dr. Luis Manuel Macías López" de Ciudad Universitaria, junto a los nombres de los universitarios que han colaborado en este momento histórico. Compartió con los presentes que, con su obra, busca expresar lo que viven los colaboradores día a día, por lo que en su intervención plasmó formas geométricas que en su conjunto representan la importancia del esfuerzo que cada uno brinda, además, un colibrí que refleja ser un mensajero de esperanza ante el contexto actual (UAA, 2021).

Finalmente, Fernando Leal Solórzano, Secretario Técnico de la FEUAA, mencionó que el mural es un pensamiento, una idea, un sueño, una semilla del roble de la esperanza, y reconoció el trabajo que 

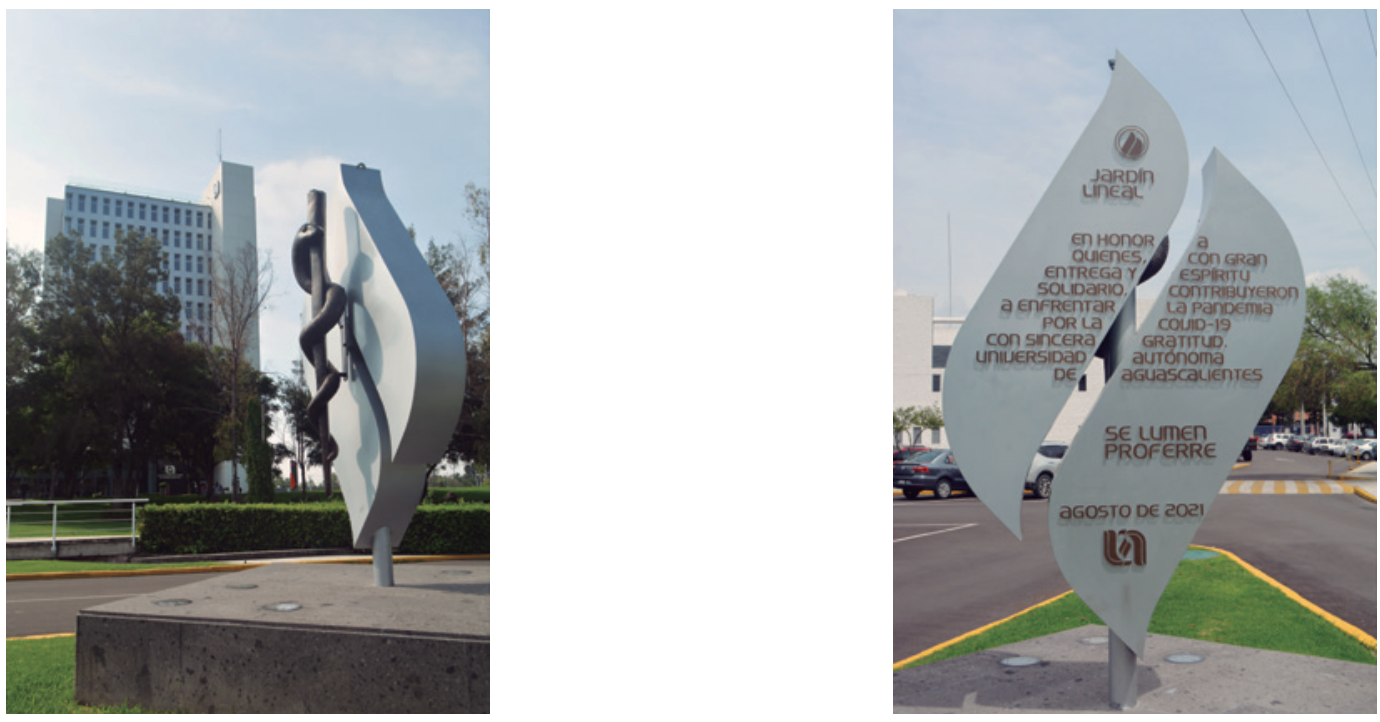

logró concretarse en este homenaje por parte de la FEUAA: "Hoy, sembramos esa luz en estos tiempos de incertidumbre, y demostramos que el ser Gallo es sinónimo de solidaridad, ayuda desinteresada, perseverancia y gratitud" (Valencia, 2021).

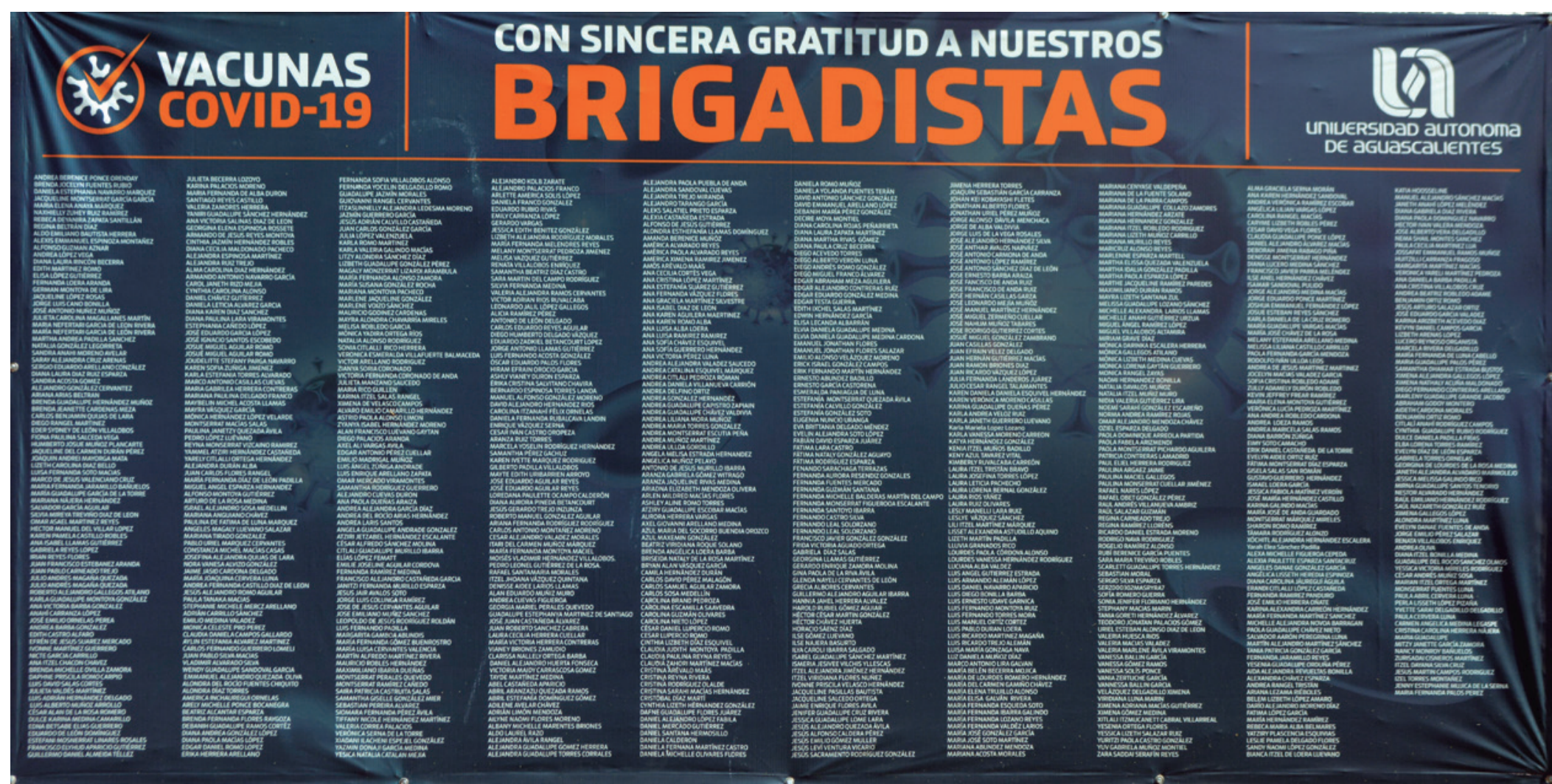

\section{Fuentes de consulta}

Universidad Autónoma de Aguascalientes. (2021, agosto). UAA, FEUAA y Gobierno del Estado develan mural en honor a brigadistas [Boletín de prensa No. 219]. Departamento de Comunicación y Relaciones Públicas. Recuperado a partir de https://bit.ly/3aXjErw

Valencia, E. (2021, 18 de agosto). Nota informativa sobre develación del mural "La voz de nuestra generación" [archivo de vídeo]. UAA Noticias. Un enfoque diferente. UAA TV. 